\title{
Associations of personality traits with internet addiction in Chinese medical students: the mediating role of attention- deficit/hyperactivity disorder symptoms
}

Meng Shi ${ }^{1,2^{*}}$ (D) and Tian Jiao Du ${ }^{2}$

\begin{abstract}
Background: Internet addiction (IA) has emerged as a public health concern, particularly among adolescents and young adults. However, few studies have been conducted in medical students. This multi-center study aimed to investigate the prevalence of IA in Chinese medical students, to examine the associations of big five personality traits with IA in the population, and to explore the possible mediating role of attention-deficit/hyperactivity disorder (ADHD) symptoms in the relationship.
\end{abstract}

Methods: Self-reported questionnaires, including Internet Addiction Test (IAT), Big Five Inventory (BFI), Adult ADHD Self-Report Scale-V1.1 (ASRS-V1.1) Screener, and socio-demographic section were distributed to clinical students at 3 medical schools in China. A total of 1264 students became the final subjects.

Results: The overall prevalence of IA among Chinese medical students was 44.7\% (IAT > 30), and 9.2\% of the students demonstrated moderate or severe IA (IAT $\geq 50$ ). After adjustment for covariates, while conscientiousness and agreeableness were negatively associated with IA, neuroticism was positively associated with it. ADHD symptoms mediated the associations of conscientiousness, agreeableness and neuroticism with IA.

Conclusion: The prevalence of IA among Chinese medical students is high. Both personality traits and ADHD symptoms should be considered when tailored intervention strategies are designed to prevent and reduce IA in medical students.

Keywords: Personality traits, Internet addiction, ADHD symptoms, Medical students

\section{Background}

The past two decades has witnessed a tremendous growth of global Internet users, with the figure increasing substantially from 0.4 billion in 2000 to 4.2 billion in 2018, and half of its current users are located in Asia [1]. It is widely acknowledged that Internet has brought huge benefits to individuals, organizations and society, like higher accessibility of information, and more communication and entertainment options. However, excessive use of

\footnotetext{
* Correspondence: mshi@cmu.edu.cn

'Department of English, School of Fundamental Sciences, China Medical University, 77 Puhe Road, Shenyang North Development Zone, Shenyang 110122, People's Republic of China

2Department of Psychology, School of Humanities and Social Sciences, China Medical University, 77 Puhe Road, Shenyang North Development Zone, Shenyang 110122, People's Republic of China
}

Internet could lead to Internet addiction (IA) [2, 3], characterized by one's inability to inhibit Internet use despite negative effects on many domains of life, such as academic performance, social relations, physical and mental health, and quality of life [2, 4-7].

IA has emerged as an important issue in the fields of public health and psychiatry. Given the psychological and developmental characteristics, university students are particularly susceptible to IA [8]. Recent studies have revealed that the prevalence of IA among college students varies significantly, ranging from $3.2 \%$ in British students, to $16.3 \%$ in Italian students, and $21.2 \%$ in Chinese students [9-11]. This wide difference in prevalence can partly be attributed to different assessment instruments. With regard to medical students, a latest

(c) The Author(s). 2019 Open Access This article is distributed under the terms of the Creative Commons Attribution 4.0 International License (http://creativecommons.org/licenses/by/4.0/), which permits unrestricted use, distribution, and 
meta-analysis has demonstrated that the pooled prevalence of IA among medical students in 6 countries is up to $30.1 \%$ [12], which is five times that of the general population [5]. Due to the stress inherent in medical education, many students are vulnerable to psychological and psychiatric disorders, such as depression and anxiety [13], which are positively associated with IA [14]. Though preliminary evidence has shown that the prevalence of IA in medical students may not be significantly different from that of other student groups [15-17], it is also revealed that the prevalence may not drop when the students become junior physicians $[17,18]$. As IA is associated with cognitive impairment [5], quality of care and safety of patients could be negatively affected if no effective intervention strategies are undertaken to deal with the issue of IA among physicians-in-training. Therefore, IA in medical students and its key related factors warrant further investigation.

Personality traits can predict one's behaviors, and it has been consistently found that they are associated with IA in different populations and cultures $[10,19,20]$. The Five-Factor Model (FFM) is the most established personality model, which recognizes that personality traits are hierarchically organized into five broad dimensions, consisting of extraversion, neuroticism, conscientiousness, agreeableness, and openness [21]. FFM is determined by biological factors, and transcends languages and cultures [22]. A meta-analytic review of big five personality traits and IA has demonstrated that all the five dimensions are significantly related to IA. While neuroticism is positively associated with IA, all the other four dimensions are negatively related to it. In terms of effect size, conscientiousness is found to be the strongest predictor, whereas openness is the weakest one [19]. However, it is worth noting that independent studies show large heterogeneity with regard to the relations between big five personality traits and IA. For instance, four dimensions were found to be predictors of IA in Iranian undergraduates with the exception of neuroticism [23]. Agreeableness and extraversion were shown to be negatively associated with IA, while openness was positively associated with it in Italian university students [10]. In Norwegian undergraduates, conscientiousness, neuroticism, and agreeableness were significant predictors [24], but only the first two dimensions were related to IA among Colombian college students [25]. It should be mentioned that after controlling for demographic variables, whereas conscientiousness and agreeableness were negatively related to IA among Chinese adolescents, all the three remaining dimensions were positively related to it [20]. As of yet, the relations between big five personality traits and IA have not been examined in Chinese university students.

Attention-deficit/hyperactivity disorder (ADHD), traditionally considered a childhood disorder, can persist into adulthood for approximately two-thirds of affected children and adolescents [26]. Two core symptoms of ADHD, being bored easily and delay aversion [27, 28], may predispose individuals to indulge in various online activities. For example, a 2-year prospective study of 2293 adolescents in Taiwan showed that ADHD was the leading risk factor for the occurrence of IA out of several psychiatric symptoms [29]. Another study carried out among Turkish university students suggested that severity of ADHD symptoms predicted severity of IA even after controlling for personality traits, depression and anxiety symptoms [30]. The meta-analysis of the associations between IA and psychiatric disorders also revealed that IA had a stronger correlation with ADHD relative to depression and anxiety [14]. Though the association between IA and ADHD is robust, the majority of the studies are conducted in Taiwan and South Korea [31], and this association has neither been examined in college students in mainland of China nor in medical students worldwide, despite the fact that a recent large survey has demonstrated that ADHD is the most common selfdisclosed disability for medical students to receive accommodations out of all types of disabilities [32].

In terms of the relations between big five personality traits and ADHD symptoms, the results are mixed. Using different assessment tools for Big Five and ADHD symptoms, Nigg et al. demonstrated that ADHD symptoms were significantly associated with low conscientiousness and agreeableness, as well as high neuroticism [33], which is congruent with the results of the metaanalytic review of the relation between the two constructs [34]. Meanwhile, Big Five were found to account for $41.4 \%$ of the variance in ADHD symptoms in a large sample of Canadian university students, with all the five dimensions being significant predictors [35]. While lower extraversion and openness were reported in ADHD patients [36], higher extraversion and lower openness were revealed in university students with ADHD symptoms [35].

Though the associations of ADHD symptoms with personality traits and IA have been examined in previous studies, the possible mediating role of the symptoms in the relation between the two variables has yet been explored. According to the vulnerability model regarding the relations between personality and psychopathology, certain personality traits can predispose individuals to certain kinds of psychopathology, including ADHD symptoms [34]. In addition, the core symptoms of ADHD may predispose individuals to IA. Thus, it was hypothesized that ADHD symptoms might function as a mediator in the relations between big five personality traits and IA. The objectives of the present study were to investigate the prevalence of IA in Chinese medical students, to examine the associations of big five personality traits with IA in this population, and to explore the 
possible mediating effects of ADHD symptoms on the associations.

\section{Methods}

\section{Study population and design}

From late September to mid-November in 2017, this multi-center cross-sectional study was carried out at three medical schools in different regions of China, including China Medical University, Guizhou Medical University, and Xiangya School of Medicine. Based on academic year, whole classes of clinical students were randomly chosen from each institution, and the students were invited to participate in the survey on a voluntary basis. A total number of 1420 questionnaires were distributed and 1312 were returned. After excluding 48 invalid questionnaires, 1264 students (effective response rate: $89.01 \%$ ) became the final subjects. The study was approved by the Institutional Review Board of China Medical University, and written informed consents were obtained from the participants according to the Declaration of Helsinki.

\section{Measurement of internet addiction}

The 20-item Internet Addiction Test (IAT) was used to evaluate IA in the students [37]. The IAT is the most widely used measure for IA worldwide and in China [15, 38, 39], and is rated on a 6-point Likert scale, with a total score ranging from 0 to 100 . According to the manual, total scores that range from 0 to 30 reflect a normal level of Internet usage; scores of 31 to 49 indicate the presence of a mild level of IA; scores of 50 to 79 reflect the presence of a moderate level, and scores from 80 to 100 indicate a severe dependence upon the Internet [40]. Developed as a unidimensional instrument, the IAT has demonstrated adequate psychometric properties, but its optimal overall structure has yet to emerge [39, 41, 42]. In the present study, the IAT was considered a one factor model, and the Cronbach's alpha for the scale was 0.916 .

\section{Measurement of personality traits}

Personality traits were measured with the 44-item Big Five Inventory (BFI) [43], which covers the five dimensions of personality traits consisting of extraversion, agreeableness, conscientiousness, neuroticism and openness. Each item is scored on a 5-point Likert scale from 1 (disagree strongly) to 5 (agree strongly). The Chinese version of BFI has shown adequate psychometric properties $[44,45]$. In this study, the Cronbach's alpha coefficients for extraversion, agreeableness, conscientiousness, neuroticism and openness were 0.733, 0.688, 0.741, 0.730 and 0.763 , respectively.

\section{Measurement of ADHD symptoms}

Adult ADHD Self-Report Scale-V1.1 (ASRS-V1.1) was developed based on the DSM-IV Criterion A symptoms of ADHD [46]. Its 6-item ASRS-V1.1 Screener was found to outperform the 18-item ASRS-V1.1 in terms of sensitivity, specificity and predictive accuracy. Each item is rated on a 5-point Likert scale, with the total score indicating severity of ADHD symptoms and risk for diagnosed ADHD [46, 47]. In the current study, the Cronbach's alpha for ASRS-V1.1 Screener was 0.680 .

\section{Demographic characteristics}

Demographic information regarding age, gender, academic year, and hometowns were obtained in the study. Hometowns were dichotomized into urban area and non-urban area.

\section{Statistical analysis}

All analyses were performed using SPSS 13.0, and the significance level of statistical tests was set at $p<0.05$. Descriptive statistics of demographic and psychological variables were indicated with mean, standard deviation $(\mathrm{SD})$, number $(\mathrm{N})$ and percentage (\%) as appropriate. Ttests and one-way ANOVA were used to compare differences of IA in categorical groups. Pearson's correlation was used to examine correlations between the continuous variables. Hierarchical regression analysis was performed to explore the effects of groups of independent variables on IA. In step 1 , the demographic variables were entered; in step 2, big five personality traits were entered; in step 3, ADHD symptoms were added. Standardized estimate $(\beta), F, R^{2}$ and $R^{2}$-changes $\left(\Delta R^{2}\right)$ for each step were provided. Asymptotic and resampling strategies, based on 5000 bootstrap samples, were used to examine the mediating role of ADHD symptoms on the associations of personality traits with IA [48]. The bias-corrected and accelerated 95\% confidence interval for each $a * b$ product was calculated to evaluate the mediation effect. A path analysis was also performed using Amos 23.0 to further validate the mediation model. All continuous variables were standardized to avoid multicollinearity before the regression analyses were performed [49].

\section{Results}

\section{Characteristics of subjects}

The demographic characteristics of the medical students and the distribution of IA in categorical variables are shown in Table 1. Among the 1264 students, 520 (41.1\%) were males, and 744 (58.9\%) were females. Their age ranged from 17 to $26(\mathrm{M}=19.74, \mathrm{SD}=1.48)$. The overall prevalence of IA among the medical students was $44.7 \%$ (IAT > 30), with $35.5,8.6$, and $0.6 \%$ of the students presenting mild $(31 \leq \mathrm{IAT} \leq 49)$, moderate $(50 \leq \mathrm{IAT} \leq 79)$, 
Table 1 Characteristics of Study Population $(N=1264)$

\begin{tabular}{lllll}
\hline Variables & No & $\%$ & IAT $($ Mean \pm SD $)$ & $P$ \\
\hline Gender & & & & \\
$\quad$ Male & 520 & $41.1 \%$ & $30.55 \pm 15.57$ & 0.232 \\
$\quad$ Female & 744 & $58.9 \%$ & $29.54 \pm 13.66$ & \\
Age group & & & & \\
$\quad$ 17-19 & 610 & $48.9 \%$ & $28.75 \pm 13.69$ & 0.004 \\
20-26 & 654 & $51.7 \%$ & $31.07 \pm 15.10$ & \\
Academic year & & & & \\
1st year & 395 & $31.3 \%$ & $27.46 \pm 13.35$ & $<0.001$ \\
2nd year & 329 & $26.0 \%$ & $30.42 \pm 14.50$ & \\
3rd year & 263 & $20.8 \%$ & $30.76 \pm 15.07$ & \\
$\quad$ 4th year & 277 & $21.9 \%$ & $32.18 \pm 14.99$ & \\
Hometown & & & & 0.046 \\
$\quad$ Urban area & 643 & $50.9 \%$ & $30.75 \pm 15.39$ & \\
$\quad$ Non-urban area & 621 & $49.1 \%$ & $29.13 \pm 13.44$ & \\
\hline
\end{tabular}

IAT Internet Addiction Test

and severe IA (IAT $\geq 80$ ), respectively. There were significant differences of IA in terms of age group $(p=0.004)$, academic year $(p<0.001)$ and hometowns $(p=0.046)$.

\section{Correlations between the variables}

The means, standard deviations and the correlations of all the continuous variables are revealed in Table 2. As demonstrated, age was not significantly related to any variable except openness. The traits of extraversion, agreeableness, conscientiousness and openness were all negatively associated with IA and ADHD symptoms, whereas neuroticism was positively associated with both of them. ADHD symptoms were positively related to IA.

\section{Associations of personality traits and ADHD symptoms with IA}

The results of the hierarchical regression of IA are presented in Table 3. While the demographic factors explained only $2.1 \%$ of the variance in IA, big five personality traits accounted for $22.2 \%$ of its variance. After adjustment for covariates, three dimensions were significantly related to IA. Specifically, both conscientiousness $(\beta=-0.318, p<0.01)$ and agreeableness $(\beta=-0.123$, $p<0.01)$ were negatively associated with IA, whereas neuroticism $(\beta=0.164, p<0.01)$ was positively associated with it. The effect of ADHD symptoms on IA was significantly positive $(\beta=0.319, p<0.01)$, explaining an additional $8.0 \%$ of the variance.

\section{Mediating role of ADHD symptoms on the associations of personality traits with IA}

Path coefficients, effect sizes of the mediator ( $a * b$ products), and $95 \% \mathrm{CI}$ for the products are presented in Table 4 . Since extraversion and openness were not significantly related to IA both before and after ADHD symptoms were entered (c and c' paths), they failed to satisfy the condition of mediation. The other three dimensions were significantly associated with ADHD symptoms (a path) and IA (c path), and ADHD symptoms were significantly associated with IA (b path). Thus, ADHD symptoms mediated the associations of conscientiousness $(a * b=-0.085,95 \%$ CI: $-0.110,-0.066)$, agreeableness $(a * b=-0.041,95 \% \mathrm{CI}:-0.063,-0.022)$ and neuroticism ( $a * b=0.068,95 \%$ CI: $0.047,0.093$ ) with IA.

To further validate the meditational model, a path analysis was performed. Examination of the goodness of fit indicated that the model was fairly adequate $\left(\mathrm{X}^{2} / \mathrm{df}=1.227\right.$, $\mathrm{CFI}=1.000, \mathrm{GFI}=0.999, \mathrm{AGFI}=0.992, \mathrm{RMSEA}=0.013$ ). The results of the path analysis were shown in Fig. 1, which were consistent with those of the regression analysis as well as the asymptotic and resampling strategies.

\section{Discussion}

To the best of our knowledge, this large multi-center study is the first one to examine the associations between big five personality traits and IA in medical students, and to explore the mediating effect of ADHD symptoms on the associations. The study showed that the overall prevalence of IA among Chinese medical students was $44.7 \%$, which was higher than $32.2 \%$ in medical students worldwide assessed by the IAT. However, caution should be taken when the prevalence is interpreted and compared since out of dozens of instruments

Table 2 Means, standard deviation (SD) and correlations of continuous variables

\begin{tabular}{|c|c|c|c|c|c|c|c|c|c|}
\hline Variables & Mean & SD & 1 & 2 & 3 & 4 & 5 & 6 & 7 \\
\hline 1. Age & 19.74 & 1.48 & 1 & & & & & & \\
\hline 2. Internet addiction & 29.95 & 14.49 & 0.045 & 1 & & & & & \\
\hline 3. Extraversion & 24.51 & 4.97 & -0.040 & $-0.159^{* *}$ & 1 & & & & \\
\hline 4. Agreeableness & 33.84 & 4.73 & -0.043 & $-0.315^{* *}$ & $0.165^{* *}$ & 1 & & & \\
\hline 5. Conscientiousness & 29.49 & 5.12 & 0.002 & $-0.419^{* *}$ & $0.264^{* *}$ & $0.342^{* *}$ & 1 & & \\
\hline 6. Neuroticism & 23.09 & 5.05 & 0.045 & $0.345^{* *}$ & $-0.367^{* *}$ & $-0.438^{* *}$ & $-0.414^{* *}$ & 1 & \\
\hline 7. Openness & 33.79 & 5.78 & $-0.058^{*}$ & $-0.159^{* *}$ & $0.415^{* *}$ & $0.185^{* *}$ & $0.349^{* *}$ & $-0.284^{* *}$ & 1 \\
\hline 8. ADHD symptoms & 9.05 & 3.39 & 0.041 & $0.462^{* *}$ & $-0.101^{* *}$ & $-0.289^{* *}$ & $-0.377^{* *}$ & $0.347^{* *}$ & $-0.174^{* *}$ \\
\hline
\end{tabular}

** $p<0.01$ (two-tailed), * $p<0.05$ (two-tailed) 
Table 3 Hierarchical linear regression analyses results

\begin{tabular}{llll}
\hline Variables & Step 1 $(\beta)$ & Step2 $(\beta)$ & Step3 $(\beta)$ \\
\hline Gender & -0.036 & $-0.073^{* *}$ & $-0.061^{*}$ \\
Age group & -0.007 & 0.010 & 0.001 \\
Hometown & $-0.062^{*}$ & -0.045 & $-0.079^{* *}$ \\
Grade group 1 & $0.094^{* *}$ & 0.054 & 0.057 \\
Grade group 2 & $0.101^{*}$ & 0.038 & 0.060 \\
Grade group 3 & $0.144^{* *}$ & $0.103^{*}$ & $0.096^{*}$ \\
Extraversion & & -0.001 & -0.027 \\
Agreeableness & & $-0.123^{* *}$ & $-0.082^{* *}$ \\
Conscientiousness & & $-0.318^{* *}$ & $-0.232^{* *}$ \\
Neuroticism & & $0.164^{* *}$ & $0.096^{* *}$ \\
Openness & & 0.012 & 0.015 \\
ADHD symptoms & & & $0.319^{* *}$ \\
$F$ & $4.400^{* *}$ & $36.536^{* *}$ & $49.660^{* *}$ \\
$R^{2}$ & 0.021 & 0.243 & 0.323 \\
$\Delta R^{2}$ & 0.021 & 0.222 & 0.080 \\
\hline
\end{tabular}

Grade group $1=2$ nd year $/ 1$ st year, Grade group $2=3$ rd year $/ 1$ st year, Grade group $3=4$ th year $/ 1$ st year

${ }^{* *} p<0.01$ (two-tailed), ${ }^{*} p<0.05$ (two-tailed)

for assessing IA, none has emerged as the diagnostic gold standard [38, 39], and different cutoffs of IAT were utilized in research [12]. Using the cutoff of IAT $\geq 50$, the prevalence of $9.2 \%$ in the current study was higher than $3.6 \%$ in American college students [50], similar to 9.7\% in Colombian college students [25], lower than $10.8 \%$ in Iranian medical students [51], 11.7\% in Chilean medical students [52], and $16.3 \%$ in Italian university students [10]. Given the affordability and easy Internet accessibility of smartphones, almost all the university students possess smartphones in China today, and they are often found to use smartphones during lectures, engaging in activities not related to academic study, such as using social media and playing online games. This phenomenon is in line with the finding of a recent study which showed that 95\% Brazilian medical students reported using their smartphones inside the classroom for non-medical related activities, and nearly a third of the students used them "always" or "almost always" [53]. The overall prevalence of IA among Chinese medical students was similar to the rate of anxiety symptoms (47.3\%) in this population [54], suggesting that IA, as a probable psychological or psychiatric disorder, might be largely neglected in the past, and should be given adequate attention from all parties involved.

After adjustment for demographic factors, three personality traits significantly predicted IA in the students. Based on the absolute value of standardized $\beta$, conscientiousness, neuroticism, and agreeableness contributed to the variance in IA. Among the three dimensions, conscientiousness was the strongest predictor, which was correspondent with the result of the meta-analysis of the relations between personality traits and IA [19]. Conscientiousness reflects individual differences in following socially prescribed impulse control that facilitates taskand goal-directed behaviors, such as thinking before acting, planning and organizing tasks, and delaying gratification [43]. High levels of conscientiousness are correlated with reduced exposure to stress, increased appraisal of coping abilities, cognitive restructuring, and higher levels of control in stressful contexts $[55,56]$. As conscientiousness-related traits are negatively related to a variety of health-risk behaviors [57], conscientious individuals can choose, create, and evoke healthier environments [58]. They are self-disciplined, diligent and goal striving, so that they can have better control of Internet use, and refrain from becoming addicted to it. In contrast, individuals with low conscientiousness are prone to impulsivity and disorganization, and tend to procrastinate $[59,60]$. Internet provides these people opportunities to procrastinate on their tasks and engage in their preferred online activities [61].

The positive association between neuroticism and IA is consistent with the results of many prior studies [19, 24, 25]. Individuals with high levels of neuroticism are characterized by feeling anxious, nervous, sad and tense [43], and they tend to see people and events in a more negative light and are oversensitive to environments. Neuroticism consistently emerges as an important predictor of negative social

Table 4 Mediating role of ADHD on the associations of personality traits with Internet addiction

\begin{tabular}{|c|c|c|c|c|c|}
\hline \multirow[t]{2}{*}{ Predictors } & \multicolumn{4}{|c|}{ Path coefficients } & \multirow[t]{2}{*}{$a * b(95 \% \mathrm{Cl})$} \\
\hline & $c$ & $a$ & $b$ & $c^{\prime}$ & \\
\hline Extraversion & -0.001 & $0.082^{* *}$ & $0.318^{* *}$ & -0.027 & $0.026(0.007,0.048)$ \\
\hline Agreeableness & $-0.123^{* *}$ & $-0.129^{* *}$ & $0.318^{* *}$ & $-0.082^{* *}$ & $-0.041(-0.063,-0.022)$ \\
\hline Conscientiousness & $-0.317^{* *}$ & $-0.269^{* *}$ & $0.318^{* *}$ & $-0.231^{* *}$ & $-0.085(-0.110,-0.066)$ \\
\hline Neuroticism & $0.163^{* *}$ & $0.214^{* *}$ & $0.318^{* *}$ & $0.095^{* *}$ & $0.068(0.047,0.093)$ \\
\hline Openness & 0.012 & -0.009 & $0.318^{* *}$ & 0.015 & $-0.003(-0.022,0.017)$ \\
\hline
\end{tabular}

$c$ : associations of personality traits with Internet addiction; $a$ : associations of personality traits with ADHD symptoms; $b$ : associations of ADHD symptoms with Internet addiction after controlling for the predictor variables; $c$ ': associations of personality traits with Internet addiction after adding ADHD symptoms as mediator; $a * b$ : the product of a and b; $95 \% \mathrm{Cl}$ : the bias-corrected and accelerated $95 \%$ confidence interval

Gender, age group, hometown, and grade year were covariates. ${ }^{*} p<0.01$ (two-tailed) 


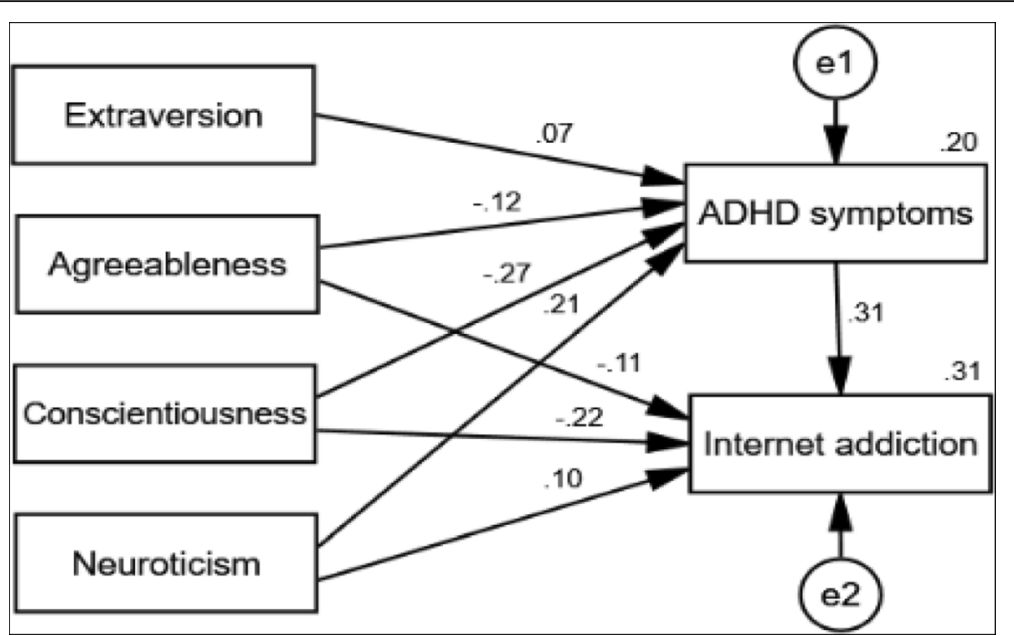

Fig. 1 Path analysis depicting direct and indirect effects of personality traits on Internet addiction. Standardized coefficients are presented, and covariates were included in the model but are not presented for simplicity

relations [62]. Compared with less neurotic ones, individuals with high levels of neuroticism are more likely to perceive and receive less social support, and experience more negative interactions within their social networks [63]. Besides, neuroticism also predicts maladaptive coping strategies, such as avoidance, withdrawal, and other emotion-oriented strategies [56]. Thus neurotic individuals may turn to Internet to cope with stress and loneliness facing them in reality.

Agreeableness refers to individual differences in people's interest in the needs and well-being of others, and is characterized by social adaptability and emotional support [43]. The negative association of agreeableness with IA found in the study is in line with the results of previous research $[10,23,24]$. While agreeable ones are motivated to avoid emotions that may result in interpersonal conflicts [64], less agreeable individuals are more likely to endorse adversarial attitudes towards people around them. Due to the lack of social connections and appropriate social skills, disagreeable people tend to have more disposable time. They may avoid social interactions in reality and turn to Internet to fulfill certain social roles in virtual reality, and thus are more likely to become addicted to Internet than their counterparts.

Personality traits were not only directly associated with IA, but also indirectly associated with it through ADHD symptoms. ADHD symptoms mediated the associations of conscientiousness, agreeableness and neuroticism with IA in the students. Higher scores on conscientiousness and agreeableness were related to lower levels of ADHD symptoms, which in turn were related to lower levels of IA. In contrast, higher scores on neuroticism were associated with higher levels of ADHD symptoms, which were associated with higher levels of IA. While the robust associations of ADHD with personality traits of conscientiousness, agreeableness and neuroticism, as well as IA have been confirmed by prior meta-analyses [14, 34], this study examined the mediating effects of ADHD symptoms on the associations of the three personality traits with IA. Conscientiousness is the personality trait that is most strongly related to ADHD symptoms, and low conscientiousness can predict problems in attention and organization [33]. The core features of neuroticism, feeling anxious and nervous, can interfere with one's cognition and contribute to ADHD symptoms [34]. Low agreeableness is strongly related to aggressive, intrusive, and delinquent behaviors of ADHD symptoms [33]. Meanwhile, Internet provides multiple opportunities for individuals with ADHD symptoms to meet their psychological needs, and thus they may gradually become addicted.

The implication of the mediation effects is that intervention strategies for IA may consider treatment of ADHD symptoms. Psychosocial treatment is an effective treatment option for adults with ADHD, especially when medication alone fails to work or its side effects are a concern. Cognitive-behavioral therapy, often incorporating modules regarding distractibility, organizational skills and cognitive restructuring, can be tailored to successfully treat ADHD [65-67]. Given that ADHD is the top contributing factor for medical students to receive accommodations [32] and there are high comorbidities of ADHD with other psychiatric disorders [66], welldesigned studies are needed to evaluate the intervention effects of tailored cognitive-behavioral therapy to deal with ADHD symptoms in this population.

Several limitations of the study should be acknowledged. First, due to the cross-sectional nature, causality of the involved constructs cannot be determined based on the available data and analysis, and the findings should be confirmed by prospective cohort studies in the future. Second, all data were obtained through self- 
reported questionnaires, which might introduce response bias. Third, despite the multi-center design, before generalizing the results, more studies should be carried out in other nations where different cultures and medical education systems exist.

\section{Conclusion}

This study revealed that the prevalence of IA among Chinese medical students is high, which warrants more attention from all parties involved. Three dimensions of big five personality traits significantly predict IA in the students. While neuroticism is a risk factor for IA, conscientiousness and agreeableness function as protective factors. ADHD symptoms mediate the associations of the three personality traits with IA. Thus, both personality traits and ADHD symptoms should be taken into account when tailored intervention strategies are designed to prevent and reduce IA in medical students.

\section{Abbreviations}

ADHD: Attention-deficit/hyperactivity disorder; ASRS-V1.1: Adult ADHD SelfReport Scale-V1.1; BFI: Big Five Inventory; FFM: Five-Factor Model; IA: Internet addiction; IAT: Internet Addiction Test

\section{Acknowledgements}

The authors would like to express sincere appreciation to all the students who participated in the study.

\section{Authors' contributions}

Conceived and designed the experiments: MS, TJD. Analyzed the data: TJD, MS. Wrote the paper: MS, TJD. Both authors read and approved the final version of the manuscript.

\section{Funding}

This study was supported by China Medical University Research Program (YDJK2018008, 3110118063), and Liaoning Department of Educaiton Research Program (2018-387, LQNR201705). The funders had no final role in the study design, collection, analysis or interpretation of the data, writing of the manuscript, or the decision to submit the paper for publication.

\section{Availability of data and materials}

The datasets used and/or analyzed during the current study are available from the corresponding author on reasonable request.

\section{Ethics approval and consent to participate}

All the subjects provided written informed consents and the study procedures were approved by the Institutional Review Board of China Medical University.

\section{Consent for publication}

Not applicable.

\section{Competing interests}

The authors declare that they have no competing interests.

Received: 9 February 2019 Accepted: 5 June 2019

Published online: 17 June 2019

\section{References}

1. Miniwatts Marketing Group. World internet usage and population statistics. 2018. https://www.internetworldstats.com/stats.htm. Accessed 10 Feb 2019.

2. Chou C, Condron L, Belland JC. A review of the research on internet addiction. Educ Psychol Rev. 2005:17(4):363-88.

3. Kuss DJ, Griffiths MD, Karila L, Billieux J. Internet addiction: a systematic review of epidemiological research for the last decade. Curr Pharm Des. 2014;20(25):4026-52.
4. Cao H, Sun Y, Wan Y, Hao Y, Tao F. Problematic internet use in Chinese adolescents and its relation to psychosomatic symptoms and life satisfaction. BMC Public Health. 2011;11:802.

5. Cheng C, Li AY. Internet addiction prevalence and quality of (real) life: a meta-analysis of 31 nations across seven world regions. Cyberpsychol Behav Soc Netw. 2014;17(12):755-60.

6. Li W, O'Brien JE, Snyder SM, Howard MO. Characteristics of internet addiction/pathological internet use in U.S. university students: a qualitativemethod investigation. PLoS One. 2015;10(2):e0117372.

7. Kim YJ, Jang HM, Lee $Y$, Lee D, Kim DJ. Effects of internet and smartphone addictions on depression and anxiety based on propensity score matching analysis. Int J Environ Res Public Health. 2018;15(5):859.

8. Kandell JJ. Internet addiction on campus: the vulnerability of college students. CyberPsychol Behav. 1998;1(1):11-7.

9. Kuss DJ, Griffiths MD, Binder JF. Internet addiction in students: prevalence and risk factors. Comput Human Behav. 2013;29(3):959-66.

10. Servidio R. Exploring the effects of demographic factors, internet usage and personality traits on internet addiction in a sample of Italian university students. Comput Human Behav. 2014;35:85-92.

11. Yan W, Li Y, Sui N. The relationship between recent stressful life events, personality traits, perceived family functioning and internet addiction among college students. Stress Health. 2014;30(1):3-11.

12. Zhang MWB, Lim RBC, Lee C, Ho RCM. Prevalence of internet addiction in medical students: a meta-analysis. Acad Psychiatry. 2018;42(1):88-93.

13. Dyrbye LN, Thomas MR, Shanafelt TD. Systematic review of depression, anxiety, and other indicators of psychological distress among U.S. and Canadian medical students. Acad Med. 2006;81:354-73.

14. Ho RC, Zhang MW, Tsang TY, Toh AH, Pan F, Lu Y, et al. The association between internet addiction and psychiatric co-morbidity: a meta-analysis. BMC Psychiatry. 2014;14:183.

15. Li L, Xu DD, Chai JX, Wang D, Li L, Zhang L, et al. Prevalence of internet addiction disorder in Chinese university students: a comprehensive metaanalysis of observational studies. J Behav Addict. 2018;7(3):610-23.

16. Krishnamurthy S, Chetlapalli SK. Internet addiction: prevalence and risk factors: a cross-sectional study among college students in Bengaluru, the Silicon Valley of India. Indian J Public Health. 2015;59(2):115-21.

17. Chaudhari B, Menon P, Saldanha D, Tewari A, Bhattacharya L. Internet addiction and its determinants among medical students. Ind Psychiatry J. 2015;24(2):158-62

18. Prakash S. Internet addiction among junior doctors: a cross-sectional study. Indian J Psychol Med. 2017;39(4):422-5.

19. Kayiş AR, Satici SA, Yilmaz MF, Şimşek D, Ceyhan E, Bakioğluc F. Big fivepersonality trait and internet addiction: a meta-analytic review. Comput Human Behav. 2016;63:35-40.

20. Zhou Y, Li D, Li X, Wang Y, Zhao L. Big five personality and adolescent internet addiction: the mediating role of coping style. Addict Behav. 2017; 64:42-8.

21. Markon KE, Krueger RF, Watson D. Delineating the structure of normal and abnormal personality: an integrative hierarchical approach. J Pers Soc Psychol. 2005;88:139-57.

22. McCrae RR, PJr C. A five factor theory of personality. In: Pervin LA, editor. Handbook of personality: theory and research. New York, NY: Guilford Press; 1999. p. 139-53.

23. Rahmani S, Lavasani MG. The relationship between internet dependency with sensation seeking and personality. Procedia Soc Behav Sci. 2011;30(30): 272-7.

24. Andreassen CS, Griffiths MD, Gjertsen SR, Krossbakken E, Kvam S, Pallesen S. The relationships between behavioral addictions and the five-factor model of personality. J Behav Addic. 2013;2(2):90-9.

25. Puerta-Cortés DX, Carbonell X. The model of big five personality factors and problematic internet use in Colombian youth. Adicciones. 2014;26(1):54-61.

26. Turgay A, Goodman DW, Asherson P, Lasser RA, Babcock TF, Pucci ML, et al. Lifespan persistence of ADHD: the life transition model and its application. J Clin Psychiatry. 2012;73(2):192-201.

27. Castellanos FX, Tannock R. Neuroscience of attention-deficit/ hyperactivity disorder: the search for endophenotypes. Nat Rev Neurosci. 2002;3(8):617-28.

28. Diamond A. Attention-deficit disorder (attention-deficit/ hyperactivity disorder without hyperactivity): a neurobiologically and behaviorally distinct disorder from attention-deficit/hyperactivity disorder (with hyperactivity). Dev Psychopathol. 2005;17(3):807-25. 
29. Ko CH, Yen JY, Chen CS, Yeh YC, Yen CF. Predictive values of psychiatric symptoms for internet addiction in adolescents: a 2-year prospective study. Arch Pediatr Adolesc Med. 2009;163(10):937-43.

30. Dalbudak E, Evren C. The relationship of internet addiction severity with attention deficit hyperactivity disorder symptoms in Turkish university students; impact of personality traits, depression and anxiety. Compr Psychiatry. 2014;55(3):497-503.

31. Wang BQ, Yao NQ, Zhou X, Liu J, Lv ZT. The association between attention deficit/hyperactivity disorder and internet addiction: a systematic review and meta-analysis. BMC Psychiatry. 2017;17(1):260.

32. Meeks LM, Herzer KS. Prevalence of self-disclosed disability among medical students in US allopathic medical schools. JAMA. 2016;316:2271-2.

33. Nigg JT, John OP, Blaskey LG, Huang-Pollock CK, Willcutt EG, Hinshaw SP, et al. Big five dimensions and ADHD symptoms: links between personality traits and clinical symptoms. J Pers Soc Psychol. 2002;83(2):451-69.

34. Gomez R, Corr PJ. ADHD and personality: a meta-analytic review. Clin Psychol Rev. 2014;34(5):376-88.

35. Parker JDA, Majeski SA, Collin VT. ADHD symptoms and personality: relationships with the five-factor model. Persd Individ Dif. 2004;36(4):977-87.

36. Jacob CP, Romanos J, Dempfle A, Heine M, Windemuth-Kiesellbach C, Kruse A, et al. Co-morbidity of adult attention-deficit/hyperactivity disorder with focus on personality traits and related disorders in a tertiary referral center. Eur Arch Psychiatry Clin Neurosci. 2007:257(6):309-17.

37. Young KS. Internet addiction: the emergence of a new clinical disorder. CyberPsychol Behav. 1998;1(3):237-44.

38. Poli R. Internet addiction update: diagnostic criteria, assessment and prevalence. Neuropsychiatry. 2017;7(1):4-8.

39. Laconi S, Rodgers RF, Chabrol H. The measurement of internet addiction: a critical review of existing scales and their psychometric properties. Comput Human Behav. 2014;41:190-202.

40. Young KS. Clinical assessment of internet-addicted clients. In: Young KS, de Abreu CN, editors. Internet addiction: a handbook and guide to evaluation and treatment. Hoboken: Wiley; 2011. p. 19-34.

41. Moon SJ, Hwang JS, Kim JY, Shin AL. Bae SM5 Kim JW. Psychometric properties of the internet addiction test: a systematic review and metaanalysis. Cyberpsychol Behav Soc Netw. 2018;21 (8):473-84.

42. Faraci $P$, Craparo G, Messina R, Severino S. Internet addiction test (IAT): which is the best factorial solution? J Med Internet Res. 2013;15(10):e225.

43. John OP, Srivastava S. The big five trait taxonomy: history, measurement, and theoretical perspectives. In: Pervin LA, John OP, editors. Handbook of personality: theory and research. New York: Guilford Press; 1999. p. 102-38.

44. Carciofo R, Yang J, Song N, Du F, Zhang K. Psychometric evaluation of Chinese-language 44-item and 10-item big five personality inventories, including correlations with chronotype, mindfulness and mind wandering. PLoS One. 2016;11(2):e0149963.

45. Wang JL, Jackson LA, Zhang DJ, Su ZQ. The relationships among the big five personality factors, self-esteem, narcissism, and sensation-seeking to Chinese university students' uses of social networking sites (SNSs). Comput Human Behav. 2012;28(6):2313-9.

46. Kessler RC, Adler L, Ames M, Demler O, Faraone S, Hiripi E, et al. The World Health Organization adult ADHD self-report scale (ASRS): a short screening scale for use in the general population. Psychol Med. 2005;35(2):245-56.

47. Kessler RC, Aler LA, Gruber MJ, Sarawate CA, Spencer T, Van Brunt DL. Validity of the World Health Organization adult ADHD self-report scale (ASRS) screener in a representative sample of health plan members. Int J Methods Psychiatr Res. 2007;16(2):52-65.

48. Preacher KJ, Hayes AF. Asymptotic and resampling strategies for assessing and comparing indirect effects in multiple mediator models. Behav Res Methods. 2008:40:879-91.

49. Cohen J, Cohen P, West SG, Aiken LS. Applied multiple regression/ correlation analysis for the behavioral sciences-third edition. Mahwah: Lawrence Erlbaum Associates; 2003.

50. Christakis DA, Moreno MM, Jelenchick L, Myaing MT, Zhou C. Problematic internet usage in US college students: a pilot study. BMC Med. 2011;9:77.

51. Ghamari F, Mohammadbeigi A, Mohammahsalehi N, Hashiani AA. Internet addiction and modeling its risk factors in medical students, Iran. Indian J Psychol Med. 2011;33(2):158-62.

52. Berner JE, Santander J, Contreras AM, Gómez T. Description of internet addiction among Chilean medical students: a cross-sectional study. Acad Psychiatry. 2014;38(1):11-4.
53. Loredo E, Silva MP, de Souza Matos BD, da Silva Ezequiel O, Lucchetti ALG, Lucchetti G. The use of smartphones in different phases of medical school and its relationship to internet addiction and learning approaches. J Med Syst. 2018;42(6):106

54. Shi M, Liu L, Wang ZY, Wang L. The mediating role of resilience in the relationship between big five personality and anxiety among Chinese medical students: a cross-sectional study. PLoS One. 2015;10(3):e0119916.

55. Bogg T, Roberts BW. The case for conscientiousness: evidence and implications for a personality trait marker of health and longevity. Ann Behav Med. 2013;45(3):278-88.

56. Connor-Smith JK, Flachsbart C. Relations between personality and coping: a meta-analysis. J Pers Soc Psychol. 2007;93(6):1080-107.

57. Bogg T, Roberts BW. Conscientiousness and health behaviors: a metaanalysis of the leading behavioral contributors to mortality. Psychol Bull. 2004:130:887-919.

58. Friedman HS, Kern ML. Personality, well-being and health. Annu Rev Psychol. 2014;65:719-42.

59. Lee DG, Kelly KR, Edwards JK. A closer look at the relationships among trait procrastination, neuroticism, and conscientiousness. Pers Individ Dif. 2006; 40(1):27-37.

60. John OP, Naumann LP, Soto CJ. Paradigm shift to the integrative Big Five trait taxonomy: History, measurement, and conceptual issues. In: John OP, Robins RW, Pervin LA, editors. Handbook of personality: theory and research. New York: Guilford Press; 2008. p. 114-58.

61. John EBV, Castille CM, Sheet TL. The five factor model of personality and employees' excessive use of technology. Comput Human Behav. 2012;28(5): 1947-53.

62. Ozer DJ, Benet-Martinez V. Personality and the prediction of consequential outcomes. Annu Rev Psychol. 2006;57:401-21.

63. Lincoln KD. Personality, negative interaction, and mental health. Soc Serv Rev. 2008;82(2):223-51.

64. Graziano WG, Tobin RM. Agreeableness: dimension of personality or social desirability artifact? J Pers. 2002;70:695-727.

65. Geffen J, Forster K. Treatment of adult ADHD: a clinical perspective. Ther Adv Psychopharmacol. 2018:8(1):25-32

66. Kolar D, Keller A, Golfinopoulos M, Cumyn L, Syer C, Hechtman L. Treatment of adults with attention-deficit/hyperactivity disorder. Neuropsychiatr Dis Treat. 2008;4(2):107-21

67. Ramsay JR, Rostain AL. Psychosocial treatments for attention-deficit/ hyperactivity disorder in adults: current evidence and future directions. Prof Psychol Res Pr. 2007;38(4):338-46.

\section{Publisher's Note}

Springer Nature remains neutral with regard to jurisdictional claims in published maps and institutional affiliations.

Ready to submit your research? Choose BMC and benefit from:

- fast, convenient online submission

- thorough peer review by experienced researchers in your field

- rapid publication on acceptance

- support for research data, including large and complex data types

- gold Open Access which fosters wider collaboration and increased citations

- maximum visibility for your research: over $100 \mathrm{M}$ website views per year

At $\mathrm{BMC}$, research is always in progress.

Learn more biomedcentral.com/submission 